
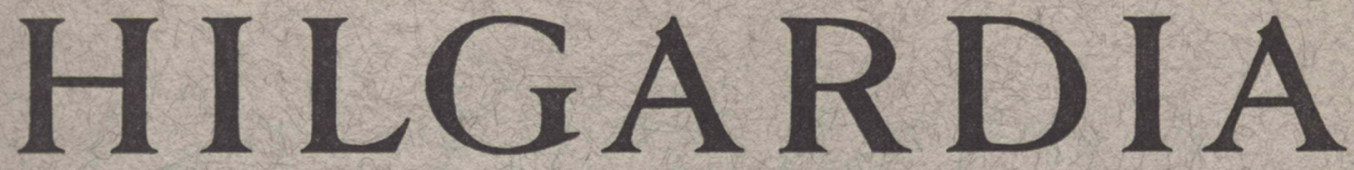

A Journal of Agricultural Science Published by the California Agricultural Experiment Station

\title{
LUMBER GRADE RECOVERY FROM A SECOND-GROWTH PINE OPERATION IN CALIFORNIA
}

MYRON E. KRUEGER, JOHN A. ZIVNUSKA, AND RUDOLF F. GRAH

UNIVERSITY OF CALIFORNIA · BERKELEY, CALIFORNIA 
The results of this study show that a system of simple log grades based upon surface characteristics may be useful in working with second-growth ponderosa pine grown at medium elevations. Such log grades can provide a basis for improved appraisals of both logs and standing timber by enabling a more accurate prediction of probable lumber grade recovery. In the study area there appeared to be little benefit from grading logs with scaling diameters of less than 14 inches by the particular system used. Above this diameter, however, the differences in lumber grade recovery between log grades increased rapidly.

The study also shows that untended stands of second-growth ponderosa pine yield a fair quality of lumber running largely to common grades. The economic aspects of improving grade recovery by pruning require separate study. 


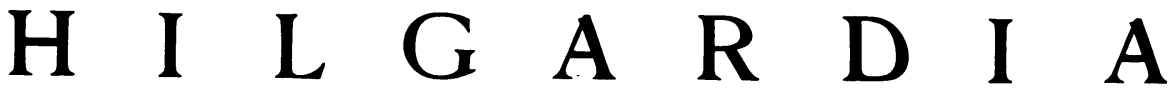

A Journal of Agricultural Science Published by

the California Agricultural Experiment Station

VoL. 22

OCTOBER, 1953

No. 10

\section{LUMBER GRADE RECOVERY FROM A SECOND-GROWTH PINE OPERATION IN CALIFORNIA ${ }^{1}$}

\section{MYRON E. KRUEGER, ${ }^{2}$ JOHN A. ZIVNUSKA, ${ }^{3}$ and RUDOLF F. GRAH ${ }^{4}$}

THE LAST decade has been marked by a high level of lumber production in California. A significant part of this production has been obtained from widespread logging in the second-growth pine stands of less than 100 years of age which are found in low and medium elevations in the Sierra Nevada pine region. The greater part of these second-growth logs are cut in small- and medium-sized circular-saw mills. In the future, increasing reliance will necessarily be placed upon such young-growth trees.

This study presents, first, a system of log grades intended for application to second-growth ponderosa pine logs and trees. Second, it reports the lumber grade recovery by diameter classes obtained from each of these log grades on a typical operation in the central Sierra region. Third, the study includes grade recovery, overrun, and sawing practices of a small circular-saw mill that appears to be fairly representative of such mills in this region.

The present work may be considered as the second in a series of studies needed to determine the lumber grade recovery of ponderosa pine on the basis of log diameter and log grade in the young-growth and young growthold growth stands of the California pine region. These logs are grown under conditions ranging from very rapidly growing, open, even-aged stands of pine to complex mixtures of young and old trees of several species. The first study, reported by Krueger ${ }^{5}$ in 1951, dealt with grade recovery from thrifty and mature classes at medium elevations. The study reported here deals with young-growth trees in essentially even-aged stands at medium elevations. Neither study considers the very rapidly grown young trees found at low elevations in the Sierra Nevada.

The relation of sawing practice to grade recovery also needs further investigation. Both studies completed to date are based on typical practices in circular-saw mills, probably of better-than-average construction.

\footnotetext{
${ }^{1}$ Received for publication January 13, 1953.

${ }^{2}$ Professor of Forestry and Associate Forester in the Experiment Station, Berkeley.

${ }^{3}$ Assistant Professor of Forestry and Assistant Forester in the Experiment Station, Berkeley.

4 Associate Agriculturist in Agricultural Extension, Berkeley.

${ }^{5}$ Krueger, Myron E. Lumber grade recovery in a circular-saw mill in California. Hilgardia 21 (3) : 81-103. 1951.
} 


\section{DESCRIPTION OF THE MILLING OPERATION}

The mill at which the study was conducted is located approximately 15 miles southeast of Groveland, California. Basically, the mill consists of a double circular head-saw and an edger. During the 9 days of the study at this mill, the average cut per 8-hour day was 20,009 board feet net scale Scribner Decimal C log rule. The number of logs cut averaged 100 per day, giving an average volume per log of 200 board feet. The mill produced primarily 2-inch boards, with 1-inch boards being cut when considerations of grade and $\log$ size made this desirable.

The rough, green lumber was then trucked to a concentration and remanufacturing yard in Turlock. As the loads were unstacked, each board was graded by a certified grader employed by this yard. The boards were then trimmed, sorted, and in some cases resawed prior to kiln drying. Immediately after drying some of the boards were graded as part of a yard study of degrade during drying. Next the boards were surfaced and then graded once again as a basis for sale.

\section{STUDY PROCEDURE}

One member of the study crew recorded the species, length, scaling diameter, and the net and gross scale Scribner Decimal C log rule of each log on the roll-way leading to the carriage. In addition, he prepared a complete diagram of each log showing the size and location of all knots. These data were recorded by $\log$ number.

The second member of the study crew marked the log and board number on each board as it was piled in fork-lift packages at the mill. For example, the mark " $285-17$ " on a board indicated that it was board no. 17 from log no. 285 . He also recorded the total number of boards in each log and the time of sawing on the head-saw for the log. A separate record was kept of all delay times during which the head-saw was not operating.

The third member of the study crew worked in the concentration and remanufacturing yard. He recorded by board numbers the dimensions and green grades as marked by the company grader. In addition, an attempt was made to obtain a record of dry grades by board numbers. However, yard procedures made it impossible to obtain a complete record of dry grades.

\section{THE SYSTEM OF LOG GRADES}

One of the objectives of the study was the development of a system of $\log$ grades suitable for application to second-growth ponderosa pine logs. Accordingly, complete knot diagrams were prepared for all logs. A sample of the form used for this purpose is presented in figure 1. Using these diagrams as a basis for sorting by grades, several possible approaches to log grading were tested with a sample of 200 of the study logs. As a result of this testing it was decided to make a complete analysis, using the system of six log grades as defined in 1938 by the Pacific Northwest Forest and Range Experiment Station. A copy of this log-grading system is presented in Appendix A. This system promised the advantages of established usage, suitability to field application, and at least as high a degree of correlation with lumber grades as any of the approaches considered. 
Further examination of the study logs showed that relatively few logs fell into each of the three upper grades and that the basis for determining lumber grade recovery for each of these log grades separately was inadequate. Therefore, it was decided to group logs of grades 1, 2, and 3 into a single grade $\mathrm{A},{ }^{8}$ but to consider grades 4,5 , and 6 separately. A complete analysis of the lumber-grade yields of all the sound 16-foot logs tallied in the study was made on this basis. The results of this analysis did not show a significant difference in the lumber grade yields of grades 4 and 5 of the study logs. Accordingly, these two grades were grouped into a composite grade B, and grade 6 was retained as grade $\mathrm{C}$.

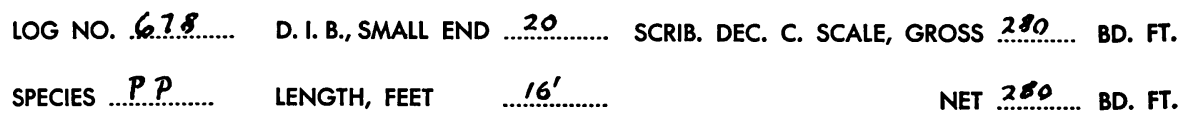

D. I. B., LARGE END

KNOT DIAGRAM:

\begin{tabular}{|c|c|c|c|c|c|c|}
\hline & 3 & 3 & 3 & 3 & 3 & 3 \\
\hline 1 & 2 & 3 & 3 & 3 & 3 & 3 \\
\hline & & & 2 & & 3 & 3 \\
\hline & 3 & 3 & 3 & 4 & 2 & \\
\hline
\end{tabular}

Fig. 1. Sample of knot-diagram form used in the study. The numbers indicate the location of the knots and their diameter in inches.

The system of three log grades used in this report is defined as follows:

Grade A. Shall have surface-clear areas which aggregate at least 50 per cent of the total surface of the log, provided that each clear area must be at least 4 feet long by one fourth the circumference in width. May display knots varying from small black knots to large sound or unsound knots but which are spaced at least 3 feet apart (longitudinally) when the knots are staggered or 6 feet apart when they are in solid whorls. (This grade is a composite of grades 1, 2, and 3 of the six-log-grade system.)

Grade B. Shall display numerous live or dead knots or both, the maximum size of which shall be proportionate to the size of the log. For a 12-inch $\log$, 4-inch live and 2-inch dead knots, for a 24-inch log, 5-inch live and 3-inch dead knots, and for a 36-inch log, 6-inch live and 4-inch dead knots are permissible. An average longitudinal spacing of not less than 2 feet between knots shall be required for logs with maximum knot sizes.

\footnotetext{
${ }^{6}$ The lumber grade recovery analysis reported in this study is based on 68 grade A logs. Graded under the six-grade system, this group consisted of 10 grade 1 logs, 16 grade 2 logs, and 42 grade 3 logs. Although it seems probable that grade A logs from untended second-growth stands will usually show a similar high proportion of grade 3 , it should be recognized that the results reported here were influenced by this particular pattern of the logs in grade $\mathrm{A}$.
} 
Logs with larger knots sha:l also be admitted to this grade if their surfaceclear areas aggregate at least one third of the total surface of the log, provided that each clear area must be at least 3 feet long by one fourth the circumference in width.

(This grade is a composite of grades 4 and 5 of the six-log-grade system.)

Grade C. Shall be rough, coarse, or densely knotted logs unsuited to either of the other two grades. (This grade corresponds to grade 6 of the six-loggrade system.)

TABLE 1

LOG GRADE A

CURVED VALUES, PERCENTAGE GRADE RECOVERY, PONDEROSA PINE, GREEN-LUMBER-GRADE BASIS

\begin{tabular}{|c|c|c|c|c|c|c|c|c|c|c|c|c|}
\hline \multirow{2}{*}{$\begin{array}{l}\text { Diam- } \\
\text { eter } \\
\text { of log, } \\
\text { inches }\end{array}$} & \multicolumn{3}{|c|}{ Selects and better } & \multirow{2}{*}{$\begin{array}{c}\text { Mould- } \\
\text { ing }\end{array}$} & \multirow{2}{*}{$\begin{array}{c}3 \\
\text { Clear }\end{array}$} & \multicolumn{3}{|c|}{ Shop } & \multicolumn{4}{|c|}{ Common } \\
\hline & $\begin{array}{l}\mathrm{B} \text { and } \\
\text { better }\end{array}$ & $\mathrm{C}$ & D & & & 1 & 2 & 3 & $1 \underset{2}{\text { and }}$ & 3 & 4 & 5 \\
\hline 13 & .. & .. & .. & 4 & 3 & 4 & 1 & . & 20 & 42 & 25 & 1 \\
\hline 14 & .. & .. & .. & 4 & 3 & 4 & 1 & .. & 21 & 42 & 24 & 1 \\
\hline 15 & .. & .. & 1 & 4 & 3 & 4 & 1 & .. & 21 & 41 & 24 & 1 \\
\hline 16 & .. & .. & 2 & 4 & 3 & 3 & 2 & .. & 21 & 40 & 24 & 1 \\
\hline 17 & .. & 1 & 2 & 4 & 3 & 3 & 4 & .. & 21 & 38 & 24 & .. \\
\hline 18 & .. & 1 & 3 & 4 & 3 & 4 & 7 & .. & 19 & 36 & 23 & .. \\
\hline 19 & .. & 2 & 3 & 5 & 3 & 4 & 12 & 1 & 15 & 32 & 23 & .. \\
\hline 20 & . & 2 & 5 & 5 & 4 & 4 & 15 & 2 & 12 & 29 & 22 & .. \\
\hline 21 & .. & 3 & 6 & 5 & 5 & 4 & 18 & 3 & 9 & 26 & 21 & .. \\
\hline 22 & .. & 3 & 8 & 7 & 5 & 4 & 18 & 3 & 8 & 24 & 20 & .. \\
\hline 23 & 1 & 3 & 9 & 8 & 5 & 4 & 19 & 3 & 7 & 22 & 19 & .. \\
\hline 24 & 1 & 4 & 12 & 9 & 5 & 2 & 18 & 4 & 7 & 20 & 18 & .. \\
\hline 25 & 1 & 5 & 16 & 8 & 4 & 2 & 17 & 4 & 8 & 18 & 17 & .. \\
\hline 26 & 1 & 6 & 18 & 8 & 4 & 1 & 17 & 4 & 8 & 16 & 17 & .. \\
\hline 27 & 1 & 8 & 19 & 7 & 4 & 1 & 17 & 5 & 7 & 15 & 16 & .. \\
\hline 28 & 1 & 8 & 20 & 7 & 4 & 1 & 17 & 6 & 7 & 13 & 16 & .. \\
\hline 29 & 1 & 8 & 21 & 7 & 4 & 1 & 17 & 6 & 7 & 12 & 16 & .. \\
\hline 30 & 1 & 8 & 22 & 6 & 4 & 2 & 17 & 6 & 7 & 11 & 16 & $\ldots$ \\
\hline
\end{tabular}

THE STUDY LOGS

During the period of this study, the mill cut 898 logs with a total net scale, Scribner Decimal C log rule, of 180,070 board feet. All logs were pondercsa pine with the exception of 5 sugar pine logs. Because of the small number involved, no separate analysis of sugar pine logs was attempted, and all logs were considered as being ponderosa pine. Of the $898 \mathrm{logs}$, 801 were 16 feet in length, 6 were 14 feet, and 91 were 12 feet. Since log grading in standing timber is based on 16 -foot logs, it was decided to use only the 16 -foot logs in the analysis of lumber grade recovery. Logs containing defects were also dropped from this part of the analysis, because defects are an additional variable which may affect the percentage distribution of the lumber grades recovered from a log of a given grade and scaling diameter. Of the 80116 foot logs, it was necessary to drop 44 from the analysis either because of defects or because of incomplete tallies of the green grades of all the boards. 
The lumber-grade-recovery analysis is based on 68 grade A logs totaling 26,587 board feet, 418 grade B logs totaling 80,950 board feet, and 271 grade $\mathrm{C} \operatorname{logs}$ totaling 41,707 board feet.

\section{RELATION OF LUMBER GRADES TO LOG GRADE AND DIAMETER}

The 757 sound 16 -foot logs for which complete records through the green grades were available were graded by the system of three log grades previously described. The green-lumber yields by grades were tallied for each

TABLE 2

LOG GRADE B

CURVEd VAlues, PERCENTAGE GRAdE RECOVERY, PONDEROSA PINE, GREEN-LUMBER-GRADE BASIS

\begin{tabular}{|c|c|c|c|c|c|c|c|c|c|c|c|c|}
\hline \multirow{2}{*}{$\begin{array}{l}\text { Diam- } \\
\text { eter } \\
\text { of log, } \\
\text { inches }\end{array}$} & \multicolumn{3}{|c|}{ Selects and better } & \multirow{2}{*}{$\begin{array}{c}\text { Mould- } \\
\text { ing }\end{array}$} & \multirow{2}{*}{$\begin{array}{c}3 \\
\text { Clear }\end{array}$} & \multicolumn{3}{|c|}{ Shop } & \multicolumn{4}{|c|}{ Common } \\
\hline & $\begin{array}{l}\mathrm{B} \text { and } \\
\text { better }\end{array}$ & $\mathrm{C}$ & D & & & 1 & 2 & 3 & $\underset{2}{1} \underset{2}{\text { and }}$ & 3 & 4 & 5 \\
\hline 8 & .. & .. & .. & 3 & .. & .. & .. & .. & 42 & 42 & 13 & .. \\
\hline 9 & .. & .. & .. & 2 & .. & .. & .. & .. & 49 & 36 & 13 & .. \\
\hline 10 & .. & .. & .. & 1 & .. & .. & .. & .. & 52 & 34 & 13 & .. \\
\hline 11 & .. & .. & .. & 1 & .. & .. & . & .. & 51 & 34 & 14 & .. \\
\hline 12 & .. & .. & .. & 1 & . & .. & 1 & .. & 46 & 35 & 17. & .. \\
\hline 13 & .. & .. & .. & 1 & .. & 1 & 1 & .. & 39 & 38 & 20 & .. \\
\hline 14 & .. & .. & .. & 1 & .. & 1 & 2 & .. & 31 & 44 & 21 & .. \\
\hline 15 & .. & .. & .. & 1 & .. & 2 & 2 & .. & 30 & 42 & 22 & 1 \\
\hline 16 & .. & .. & 1 & 1 & 1 & 2 & 2 & .. & 29 & 40 & 23 & 1 \\
\hline 17 & .. & .. & 1 & 1 & 1 & 3 & 3 & .. & 29 & 37 & 24 & 1 \\
\hline 18 & . & .. & 1 & 1 & 1 & 4 & 4 & 1 & 28 & 35 & 24 & 1 \\
\hline 19 & .. & & 1 & 2 & 1 & 5 & 6 & 2 & 25 & 34 & 23 & 1 \\
\hline 20 & .. & 1 & 1 & 2 & 1 & 6 & 10 & 2 & 21 & 32 & 23 & 1 \\
\hline 21 & .. & 1 & 1 & 2 & 1 & 7 & 13 & 2 & 18 & 30 & 23 & 2 \\
\hline 22 & .. & 1 & 1 & 2 & 1 & 8 & 16 & 3 & 15 & 28 & 23 & 2 \\
\hline 23 & .. & 1 & 2 & 3 & 1 & 8 & 19 & 3 & 11 & 27 & 23 & 2 \\
\hline 24 & .. & 1 & 2 & 3 & 1 & 9 & 23 & 4 & 8 & 24 & 23 & 2 \\
\hline 25 & .. & 1 & 3 & 3 & 2 & 9 & 26 & 4 & 5 & 23 & 22 & 2 \\
\hline 26 & .. & 1 & 4 & 4 & 2 & 10 & 29 & 4 & 3 & 21 & 21 & 1 \\
\hline 27 & .. & 1 & 5 & 4 & 2 & 10 & 30 & 4 & 3 & 20 & 20 & 1 \\
\hline 28 & .. & 1 & 6 & 4 & 2 & 11 & 32 & 4 & 3 & 18 & 18 & 1 \\
\hline 29 & .. & 1 & 7 & 4 & 1 & 13 & 32 & 4 & 3 & 18 & 16 & 1 \\
\hline 30 & .. & 1 & 7 & 4 & 1 & 14 & 33 & 4 & 3 & 18 & 14 & 1 \\
\hline
\end{tabular}

$\log$ grade by 1 -inch scaling diameter classes. The yield of each lumber grade was expressed as a percentage of the total yield of the diameter class. For the raw data summarized in this form see tables 5, 6, and 7 (Appendix B).

These percentage yields by lumber grades were plotted over scaling diameter by log grades, and freehand curves were fitted to the points. Averagegrade-recovery percentages were read from these curves for each log grade and diameter class. These average yields by lumber grades, expressed as percentages of the total log volume, are presented by log grades and diameter classes in tables 1,2 , and 3 . Figure 2 shows the same data graphically on a cumulative basis. 

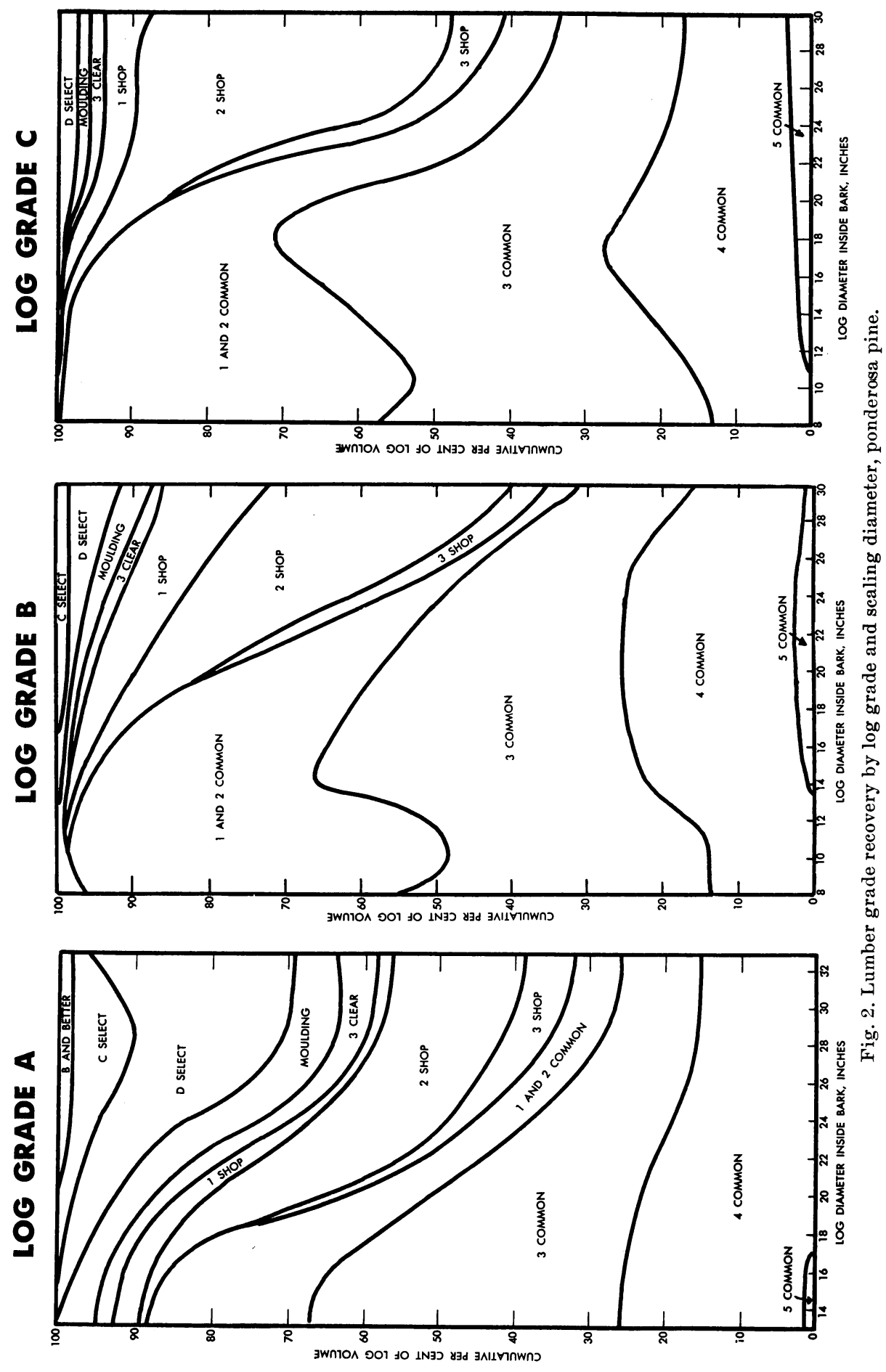
It should be recognized that the basic data show numerous irregularities and that the plotted points show a wide scatter around the curves. In addition, most of the logs observed fell within the central portion of the diameter range covered. As a result, the statistical basis for the portions of the curves covering both the very small and the larger logs of the diameter range is somewhat weak. Full evaluation of these factors can be obtained by examination of the basic data presented in tables 5,6 , and 7 .

TABLE 3

LOG GRADE C

CURVED VALUES, PERCENTAGE GRADE RECOVERY, PONDEROSA PINE, GREEN-LUMBER-GRADE BASIS

\begin{tabular}{|c|c|c|c|c|c|c|c|c|c|c|c|c|}
\hline \multirow{2}{*}{$\begin{array}{c}\text { Diam- } \\
\text { eter } \\
\text { of log, } \\
\text { inches }\end{array}$} & \multicolumn{3}{|c|}{ Selects and better } & \multirow{2}{*}{$\underset{\text { ing }}{\text { Mould- }}$} & \multirow{2}{*}{$\begin{array}{c}3 \\
\text { Clear }\end{array}$} & \multicolumn{3}{|c|}{ Shop } & \multicolumn{4}{|c|}{ Common } \\
\hline & $\begin{array}{l}\mathrm{B} \text { and } \\
\text { better }\end{array}$ & C & $\mathrm{D}$ & & & 1 & 2 & 3 & 1 and & 3 & 4 & 5 \\
\hline 8 & $\cdots$ & . & $\cdots$ & $\cdots$ & $\cdots$ & $\cdots$ & $\cdots$ & .. & 43 & 44 & 13 & .. \\
\hline 9 & .. & $\cdots$ & .. & $\cdots$ & $\cdots$ & $\cdots$ & . & .. & 46 & 41 & 13 & .. \\
\hline 10 & . & . & . & . & .. & . & 1 & .. & 47 & 38 & 14 & .. \\
\hline 11 & . & $\cdots$ & $\cdots$ & $\cdots$ & $\cdots$ & . & 1 & .. & 46 & 37 & 15 & 1 \\
\hline 12 & . & $\cdots$ & . & . & $\cdots$ & $\cdots$ & 1 & .. & 44 & 37 & 17 & 1 \\
\hline 13 & . & . & $\cdots$ & . & . & .. & 1 & .. & 41 & 38 & 19 & 1 \\
\hline 14 & .. & . & . & . & . & 1 & 1 & .. & 38 & 38 & 21 & 1 \\
\hline 15 & $\cdots$ & . & .. & .. & .. & 1 & 2 & .. & 35 & 38 & 23 & 1 \\
\hline 16 & . & . & $\cdots$ & $\ldots$ & $\cdots$ & 2 & 2 & .. & 30 & 40 & 24 & 2 \\
\hline 17 & . & $\ldots$ & $\ldots$ & 1 & .. & 2 & 2 & .. & 25 & 42 & 25 & 2 \\
\hline 18 & . & $\ldots$ & 1 & 1 & . & 3 & 3 & .. & 21 & 44 & 25 & 2 \\
\hline 19 & $\ldots$ & . & 1 & 1 & 1 & 3 & 5 & .. & 21 & 43 & 23 & 2 \\
\hline 20 & . & $\cdots$ & 1 & 1 & 1 & 3 & 8 & .. & 22 & 40 & 22 & 2 \\
\hline 21 & . & . & 2 & 1 & 2 & 3 & 10 & 2 & 25 & 33 & 20 & 2 \\
\hline 22 & $\ldots$ & . & 2 & 2 & 2 & 3 & 14 & 5 & 24 & 27 & 19 & 2 \\
\hline 23 & $\ldots$ & . & 2 & 2 & 2 & 4 & 20 & 9 & 17 & 24 & 18 & 2 \\
\hline 24 & . & $\ldots$ & 2 & 2 & 2 & 4 & 29 & 8 & 12 & 22 & 17 & 2 \\
\hline 25 &.. & . & 2 & 2 & 2 & 4 & 35 & 6 & 10 & 21 & 16 & 2 \\
\hline 26 & .. & . & 2 & 2 & 2 & 4 & 38 & 6 & 9 & 19 & 15 & 3 \\
\hline 27 & . & $\ldots$ & 2 & 2 & 2 & 4 & 40 & 6 & 9 & 18 & 14 & 3 \\
\hline 28 & . & $\ldots$ & 2 & 2 & 2 & 4 & 41 & 6 & 9 & 17 & 14 & 3 \\
\hline 29 & . & $\ldots$ & 2 & 2 & 2 & 5 & 41 & 6 & 8 & 17 & 14 & 3 \\
\hline 30 & . & . & 2 & 2 & 2 & 6 & 40 & 7 & 8 & 17 & 13 & 3 \\
\hline
\end{tabular}

The results emphasize the strong relation of grade recovery to diameter in the type of logs covered by this study. Practically no logs of less than 14-inch diameter having the surface characteristics of grade A were found. Differences in lumber grade recovery between grade B and grade C logs of less than 14-inch diameter were very minor. As would be expected, these small logs yielded almost entirely common grades of lumber, with approximately two fifths of the volume falling in number 1 and 2 common, another two fifths in number 3 common, and the remainder in number 4 common.

In the diameter range of 14 to 20 inches all three grades continued to run heavily to number 3 common, with about two fifths of the volume falling in this grade. Grade A logs showed appreciable and increasing amounts of the 
upper grades, with 20 -inch logs yielding about 10 per cent in clears and selects and 25 per cent in shop grades and moulding. Grade B logs also began to yield some of the better grades of lumber, with 20-inch logs yielding 3 per cent in clears and selects and 20 per cent in shop grades and moulding. Grade $\mathrm{C}$ logs ran more than 90 per cent to common grades in this range, although 20 -inch grade $\mathrm{C}$ logs yielded about 10 per cent in the number 1 and 2 shop grades.

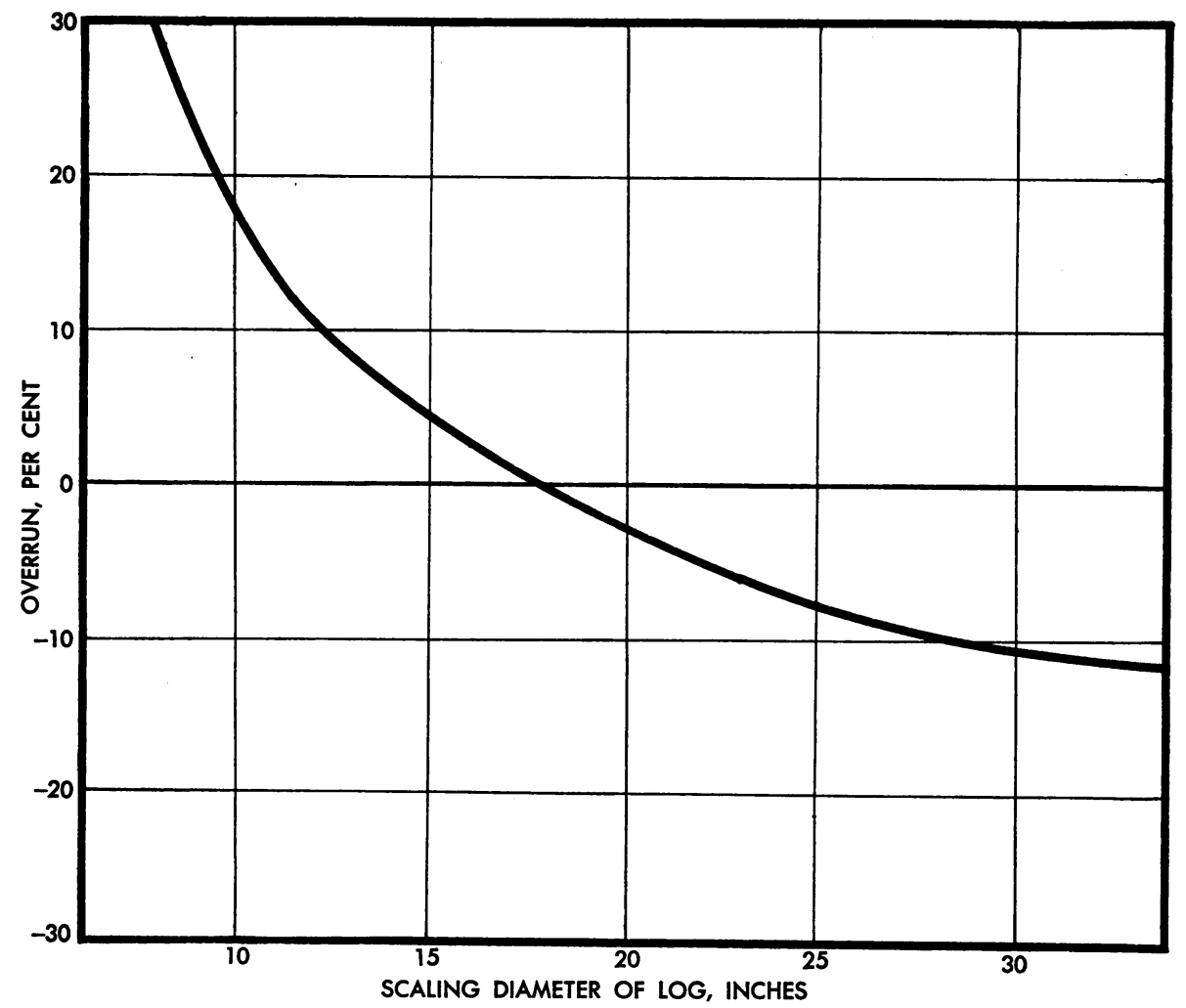

Fig. 3. Overrun curve for 16 -foot logs.

Above 20 inches in diameter, the differences in lumber grade recovery among the $\log$ grades became more pronounced. However, it was only in diameters of 26 inches and larger that grade A logs yielded as much as one fourth their volume in D select and better. These larger grade A logs also yielded nearly one fifth their volume in number 2 shop, but gave only minor amounts of number 1 shop. Only the larger grade B logs yielded 10 per cent in $\mathrm{D}$ select and better. However, these logs also yielded another 10 per cent in number 1 shop and about one third of their volume in number 2 shop. Grade C logs yielded only minor amounts of D select, moulding, and number 1 shop, but in diameters of 26 inches and larger yielded 40 per cent in number 2 shop. 


\section{OVERRUN AND UNDERRUN}

The ratio of volume lumber tally to volume log scale, Scribner Decimal C $\log$ rule, was determined by 1 -inch diameter classes for the 757 sound 16 -foot logs for which complete lumber tallies were compiled. The resulting curve of overrun and underrun by diameter classes is shown in figure 3. Logs of less than 18-inch scaling diameter yielded an overrun, while larger logs gave an underrun. For the total volume of the $757 \operatorname{logs}$, the underrun was 2.0 per cent.

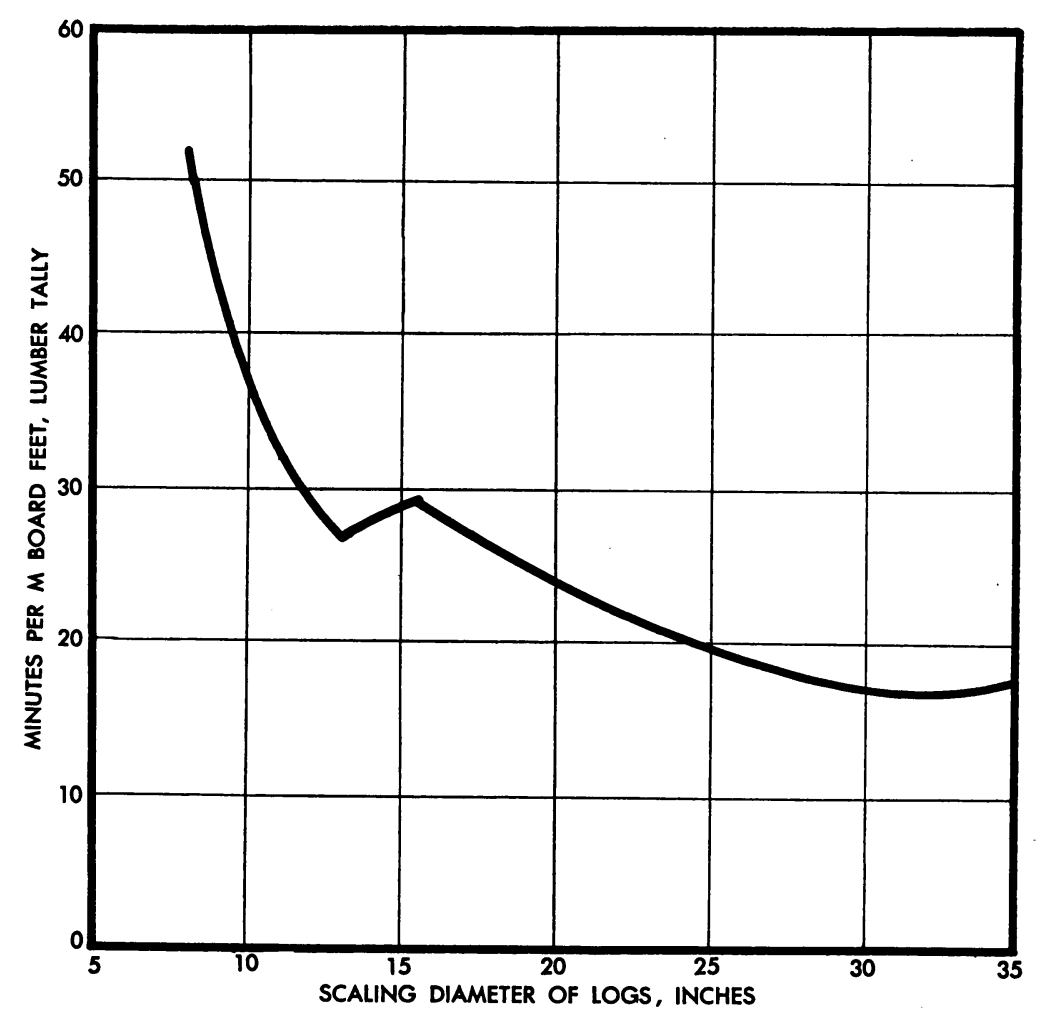

Fig. 4. Sawing time per thousand board feet, lumber tally, 16-foot ponderosa pine logs.

\section{SAWING TIME}

The cost of milling logs varies directly with the time of sawing on the head-saw. Time on the head-saw was recorded for each log to the nearest hundredth of a minute. Delay times were prorated by diameter classes over the entire $898 \operatorname{logs}$ cut during the 9-day period of the study. Using the 757 sound 16-foot logs with complete lumber tallies, sawing times per thousand board feet lumber tally were calculated by diameter classes. This relation of sawing time per thousand board feet lumber tally to scaling diameter for 16 -foot logs is shown graphically in figure 4 . The sharp discontinuity in the 


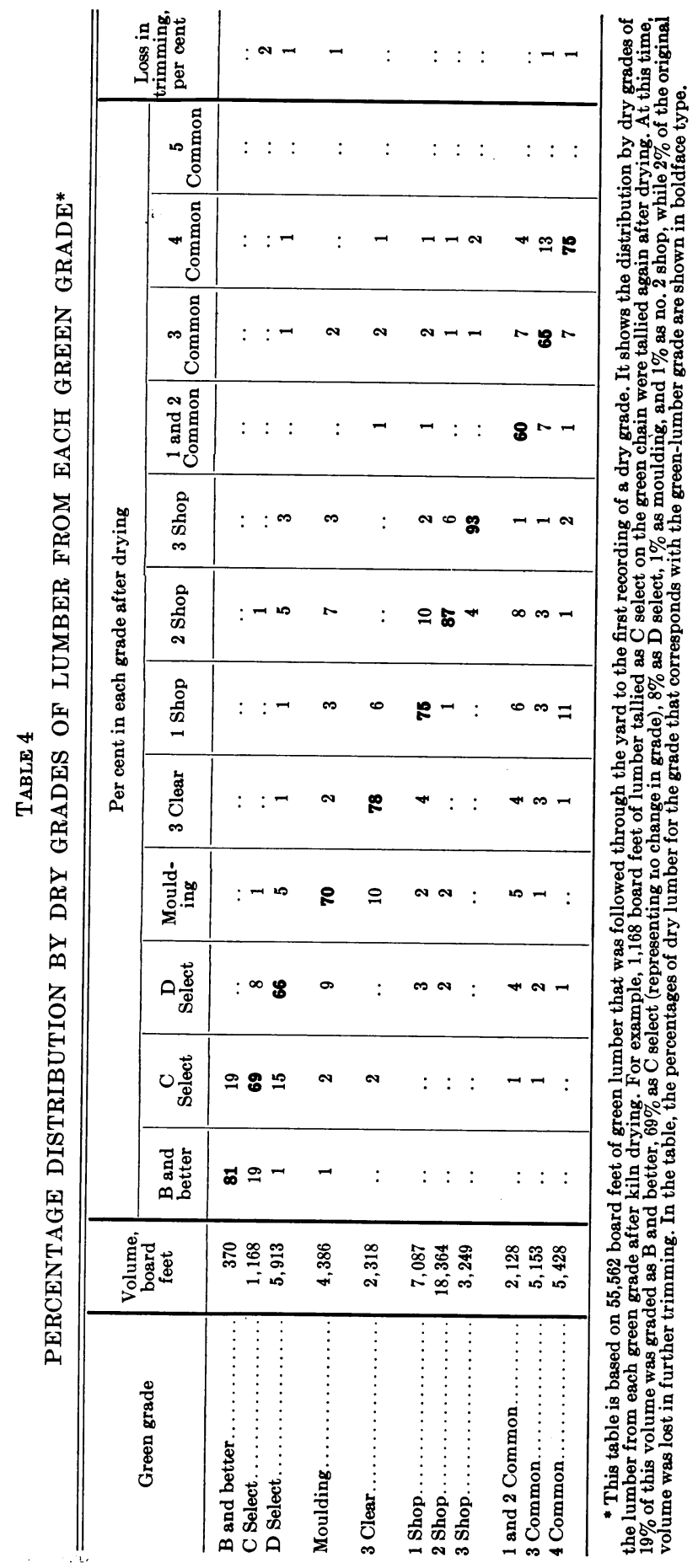


curve between 13 inches and 16 inches is due to the fact that in this diameter range sawing practice at the mill shifted from sawing the logs "alive" to sawing patterns which required turning the log on the carriage.

\section{DRY GRADES}

Since ponderosa pine lumber is normally sold dry rather than green, it is desirable to have lumber-grade-recovery data based on dry grades instead of on green grades. However, because of the lumber-handling procedures followed at the concentration and remanufacturing yard it was not possible to follow all the boards of any substantial number of logs through to the dry grades. Therefore, this analysis has been made primarily in terms of green grades.

An effort was made to tally the dry grade of every board for which a numerical designator could still be determined during the first grading after kiln drying. In all, 55,562 board feet of lumber were tallied by dry grade. These data were analyzed to determine the distribution by grades of lumber from each green grade after drying. The results of this analysis are summarized in table 4.

The analysis shows that in most cases substantial shifts in grade occurred. It should be noted that the volumes shifted upward in grade roughly equaled the volumes shifted downward. In part this upgrading was due to the yard practice of trimming to improve grade whenever possible. Although the green grader pencil-trimmed the boards as a part of his grading procedure, some additional trimming was done after drying. However, the fact that the majority of boards raised in grade had not been trimmed to shorter lengths suggests that many of the differences in grade were due to differences in grading, even though both green and dry grading were done by certified graders. Payment by the yard to the mill operator was made on the basis of green grade. Apparently where there was a legitimate doubt between grades, the lower grade was chosen. In addition, the more experienced grader worked on the shipping grades. Thus, no definite conclusions concerning degrade due to seasoning can be drawn from these data.

\section{ACKNOWLEDGMENTS}

The study was conducted at the mill operated by Hallowell, Nagy, and Hallowell near Groveland, California, and at the concentration and remanufacturing yard of Snider Forest Products Company, Turlock, California. The courtesy and coöperation of the management and of all employees at both concerns made the study possible.

Mr. Robert Baker, then (1951-1952) a laboratory assistant in the School of Forestry, assisted in the compilation and computation of results.

Thanks are gratefully extended to all. 


\section{APPENDIX A}

\section{Ponderosa Pine Log Grade Descriptions \\ As Reworded on November 1, 1.938 \\ Pacific Northwest Forest and Range Experiment Station \\ Portland, Oregon}

\section{Grade 1}

Shall be smooth and surface clear without indication of knots near the surface, providing, however, that 1 pin knot is permissible any place on the log.

\section{Grade 2}

Shall be smooth and surface clear on three faces but with knots permissible on the fourth face; or shall be smooth and surface clear on the lower three-fourths of the length, above which a few knots are permissible; or shall be smooth and surface clear to within 2 feet of the upper end, above which any number of knots are permissible. In any case 1 pin knot is permissible on the clear portion of the log.

\section{Grade 3}

Shall display knots which may vary from small black knots to large sound or unsound knots but which are spaced at least 3 feet apart (longitudinally) when the knots are staggered or 6 feet apart when they are in solid whorls. The surface clear areas must aggregate at least 50 per cent of the total surface of the log, provided that each clear area must be at least 4 feet long by one-fourth the circumference in width.

\section{Grade 4}

Shall display numerous small and medium-sized red (live) knots, provided, however, that black (dead) knots which in the grader's judgment will cut out sound beneath the surface (usually on black barked logs) are permissible. The size of the knots shall be proportionate to the size of the log. For a 12-inch log 2-inch live or 1-inch dead knots and for a 24-inch $\log 4$-inch live or 2 -inch dead knots are permissible. An average longitudinal spacing of not less than 2 feet shall be required for logs with maximum knot sizes.

\section{Grade 5}

Shall display numerous live and/or dead knots, the maximum size of which shall be proportionate to the size of the $\log$. For a 12 -inch $\log , 4$-inch live and 2 -inch dead knots, and for a 24-inch $\log$, 5-inch live and 3 -inch dead knots, and for a 36-inch log, 6-inch live and 4 -inch dead knots are permissible. An average longitudinal spacing of not less than 2 feet shall be required for logs with maximum knot sizes.

Logs with larger knots shall also be admitted to this grade if their surface clear areas aggregate at least one-third of the total surface of the log, provided that each clear area must be at least 3 feet long by one-fourth the circumference in width.

\section{Grade 6}

Shall be rough, coarse or densely knotted logs unsuited to any of the previous grades.

\section{General Considerations}

Foregoing specifications as to spacing between knots refer to distance between knot or limb edges rather than from center to center.

Defects for which deductions are made in scaling shall not be considered in determining $\log$ grades.

Standing trees shall be graded on the basis of 16 -foot logs and each log shall be graded solely on the basis of its own grade characteristics, i.e., the grade characteristics of adjoining logs shall not be allowed to influence the grader's judgment. 
APPENDIX B

TABLES OF BASIC DATA 


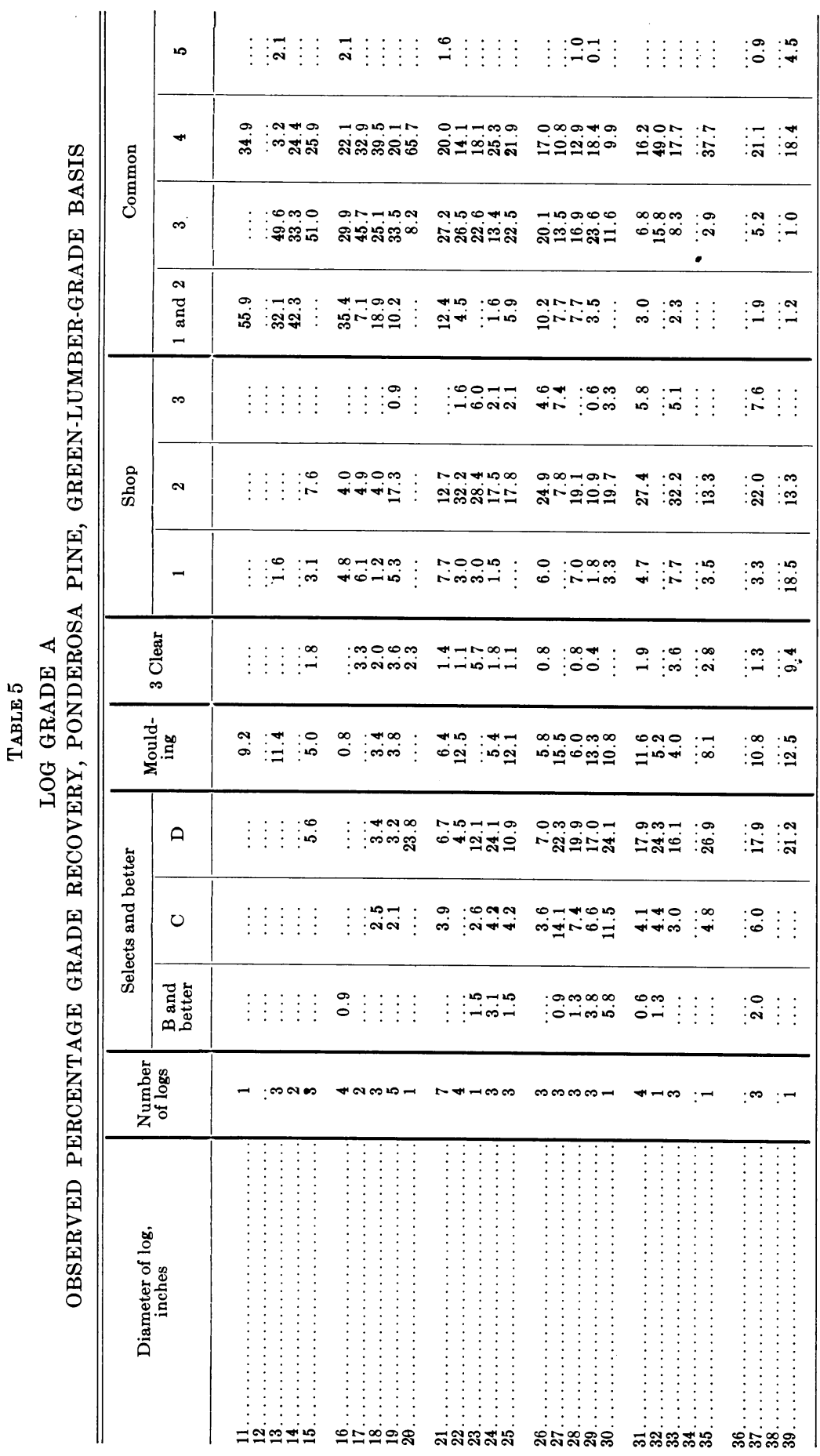




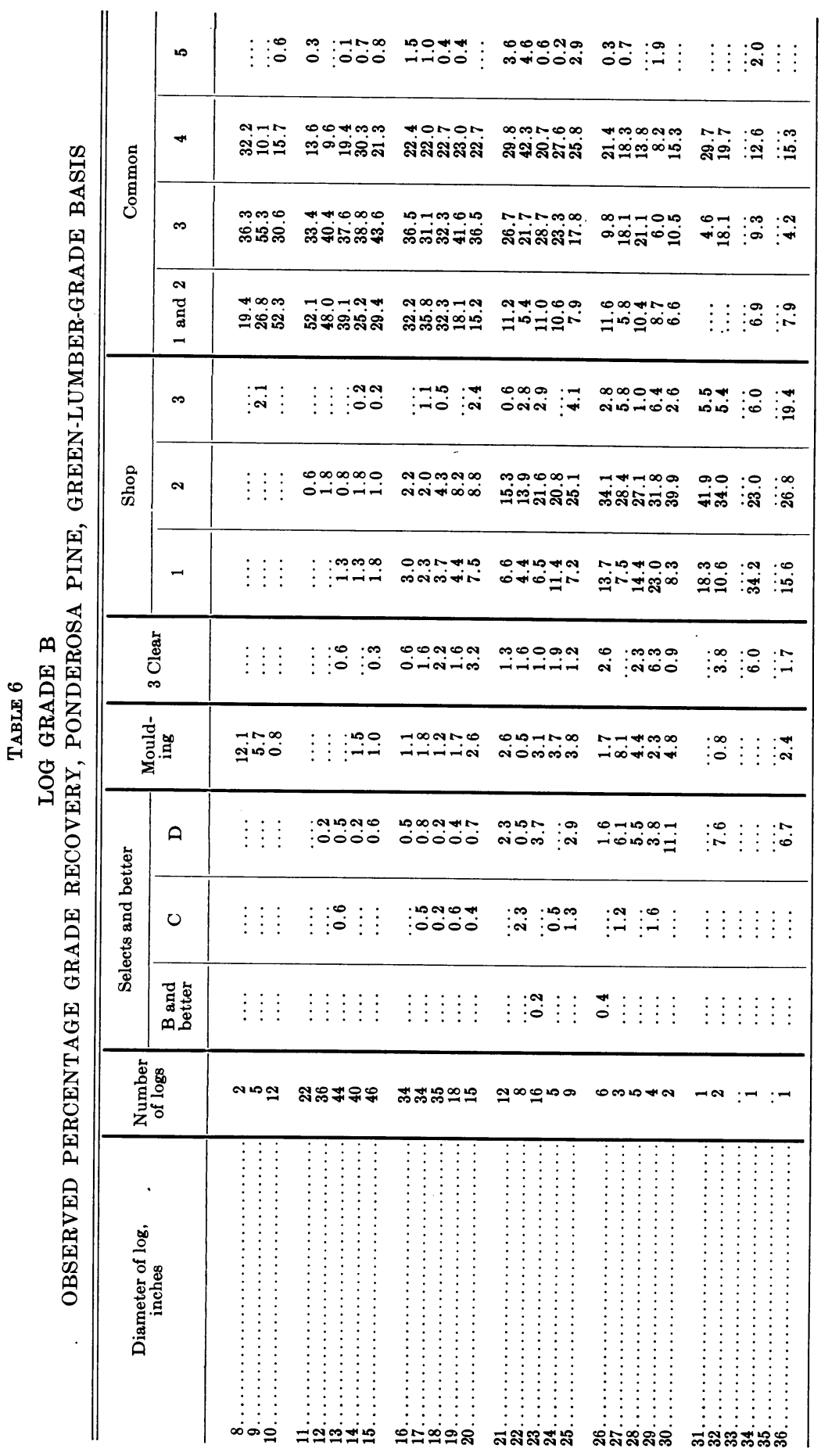




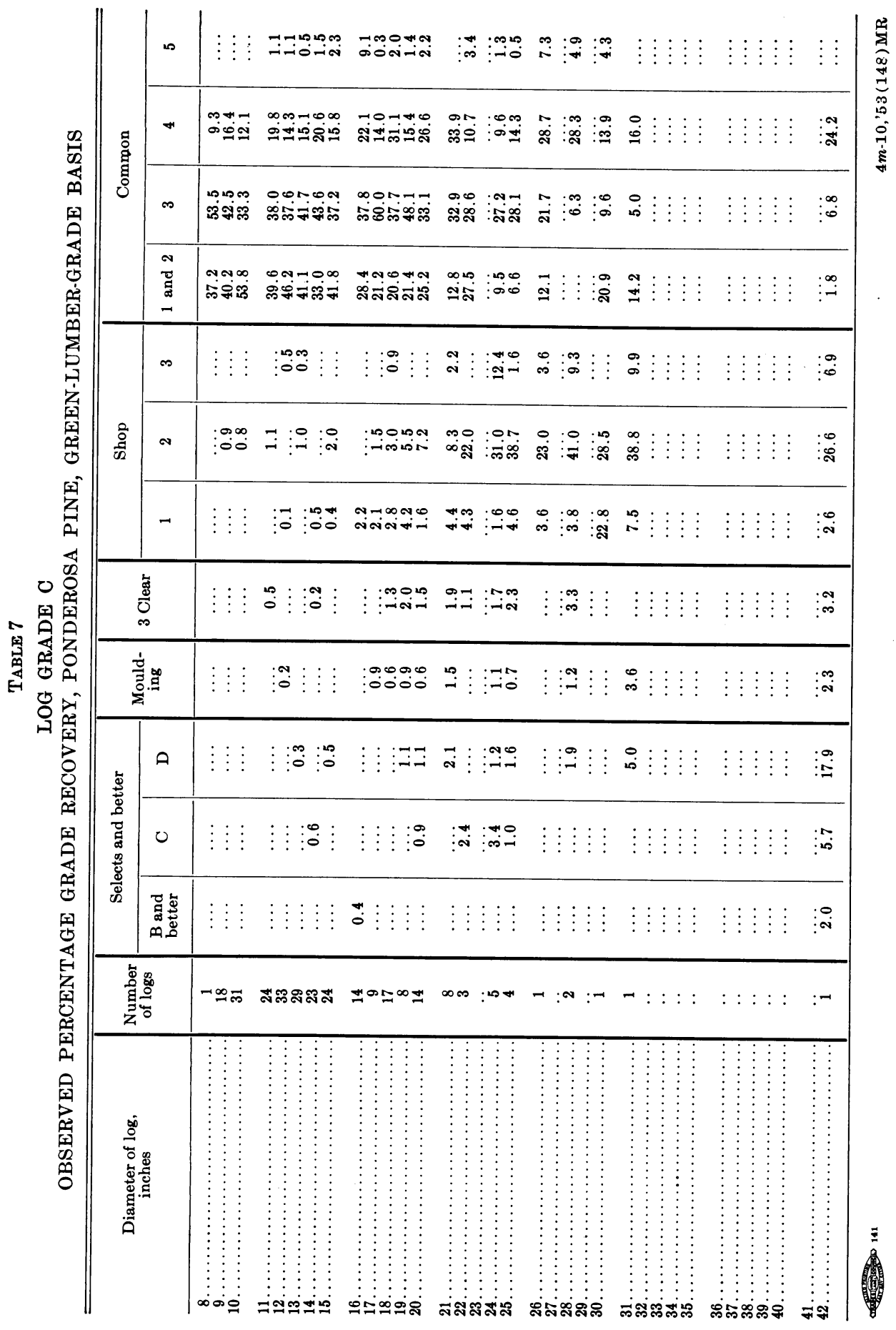


The journal Hilgardia is published at irregular intervals, in volumes of about 600 pages. The number of issues per volume varies.

Subscriptions are not sold. The periodical is sent as published only to libraries, or to institutions in foreign countries having publications to offer in exchange.

You may obtain a single copy of any issue free, as long as the supply lasts; please request by volume and issue number from:

Publications Office

College of Agriculture

Berkeley 4, California

The limit to nonresidents of California is 10 separate issues on a single order. A list of the issues still available will be sent on request. 